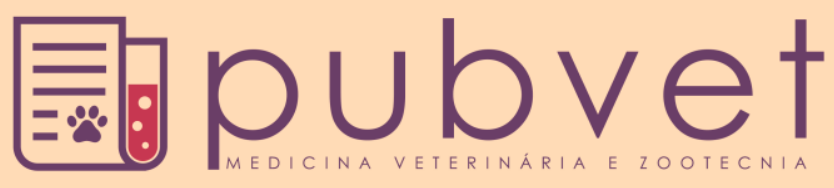

https://doi.org/10.22256/pubvet.v12n4a64.1-6

\title{
Tratamento não invasivo de Pectus Excavatum em Buldogue Inglês: Relato de caso
}

\author{
Cinthia Nayara Oliveira de Moura ${ }^{\ominus}$ 1*, Guilherme Dipp $^{2} \bullet$
}

${ }^{I}$ Acadêmicado $10^{\circ}$ períododoCursode Medicina Veterinánia, CentrodeEnsinoSuperiordosCampos Gerais-CESCAGE, PontaGrossa-PR,E-mail:cinthicvetmoura@hotmail.com ${ }^{2}$ Mestre e Professora do Curso de Medicina Veterinária, Centro de Ensino Superior dos Campos Gerais-CESCAGE, Ponta Grossa-PR, E-mail:dippdmv@gmail.com *Autor para correspondência

RESUMO. Pectus excavatum ou peito escavado é uma afecção congênita caracterizada por compressão dorso ventral e um aumento da largura torácica, em virtude do crescimento anormal do esterno e cartilagem em uma depressão condroesternal. Anomalia desenvolvida na vida intrauterina resultante de expressões genômicas herdáveis. Tratando-se de uma enfermidade rara sua etiologia ainda não é explicada, relacionada ao um gene autossômico dominante, acomete geralmente cães de raças braquicefálicas, sendo não correlacionando com predisposição sexual. Pacientes acometidos pela Pectus excavatum apresentam sinais que acometem os sistemas cardiovasculares e respiratório. $\mathrm{O}$ diagnóstico baseia-se na anamnese e radiografia torácica. O objetivo desse trabalho foi relatar um caso clinico de Pectus excavatum que obteve sucesso com o tratamento não invasivo pela utilização de uma tala externa na compressão do tórax de filhote de Buldogue inglês. A escolha desse tema deveu-se ao fato de ser uma doença com a casuística baixa em pequenos animais.

Palavras chave: Hipoplasia traqueal, peito escavado, desvio cardíaco, radiografia

\section{Non-Invasive treatment of Pectus Excavatum in a Bulldog Ingles: Case report}

\begin{abstract}
Pectus excavatum and a congenital disorder characterized in dorsal-ventral compression and hum increased chest width, in virtue of the breastbone and cartilage abnormal growth falling in a chondrosternal Depression. And this anomaly developed in intrauterine life, and may be the result of a heritable genomic expressions. In the case of a rare disease etiology, not your e explained the hum related autosomal dominant gene, usually affects brachycephalic breeds of dogs, being not correlate with sexual predisposition. For patients suffering pectus excavatum present Signs That affects the cardiovascular system and respiratory functionality. The diagnosis is based on clinical history and chest $\mathrm{x}$-ray. With the diagnosis confirmed if have a purpose of Rectification Anatomic do breastbone. The aim of this study was to report hum Case Study of pectus excavatum que achieved success with no invasive treatment by using an external splint on chest compression hum English bulldog puppy. The choice of subject was due to be the Fact A disease with a low sample animals small.
\end{abstract}

Keywords: Tracheal hypoplasia, excavated chest, heart by-pass, radiography

\section{Tratamiento no invasivo de Pectus excavatum en Bulldog Inglés: Reporte de un caso}

Pectus excavatum o pecho escavado es una afección congénita, caracterizada por compresión dorso ventral y un aumento de la anchura torácica, debido al crecimiento 
anormal del esternón y cartílago en una depresión condroesternal. Esta anomalía se desarrolla en la vida intrauterina, pudiendo ser resultante de expresiones genómicas heredables. Tratándose de una enfermedad rara su etiología aún no se explica, relacionada con el gen autosómico dominante, acomete generalmente perros de razas braquiocefálicas, siendo no correlacionando con predisposición sexual. Los pacientes afectados por la PE, presentan signos que afectan la funcionalidad de los sistemas cardiovasculares y respiratorios. El diagnóstico se basa en la anamnesis y la radiografía torácica. Con el diagnóstico confirmado se tiene la finalidad de la corrección anatómica del esternón. El objetivo de este trabajo fue relatar un caso clínico de Pectus excavatum que obtuvo éxito con el tratamiento no invasivo por la utilización de un tablilla externa en la compresión del tórax en un cachorro de Bulldog inglés. La elección de este tema se debió al hecho de ser una enfermedad con la casuística baja en pequeños animales.

Palabras clave: Hipoplasia traqueal, pecho escavado, desvío cardiaco, radiografía

\section{Introdução}

As deformidades da parede torácica anterior são atribuídas universalmente como deformidades pectus. São considerados dois tipos de deformidades: o pectus excavatum e pectus carinatum. $\mathrm{O}$ pectus excavatum é um estreitamento ventral- dorsal do tórax, também conhecido como o "peito de funil" ou " peito escavado', considerada uma enfermidade rara em pequenos animais (Martins et al., 2014).

Pectus excavatum é uma deformação no tórax pelo crescimento anormal do esterno e cartilagem resultando em uma depressão condroesternal. Sua etiologia ainda não é clara, as teorias propostas incluem resultado de uma expressão genômica herdavél adquirida na vida intrauterina, encurtamento do tendão do diafragma, anormalidades na pressão intrauterina $e$ deficiência congênita da musculatura na porção craniana do diafragma (Molina-Díaz \& Aguirre, 2014). Fossum (2014) afirma que pacientes com Pectus escavatum apresentam concomitante com anormalidades em funções respiratórias e cardiovasculares, tais como hipoplasia traqueal e desvio do coração, sendo sua avaliação objetiva por diagnóstico por imagem.

Esse relato de caso trata sobre um cão da raça Buldogue inglês diagnosticado com PE, corrigido clinicamente a partir de uma técnica não invasiva com a aplicação de uma tala, tendo como objetivo relatar um tratamento não invasivo, por ser uma doença de pouco acometimento em animais de pequeno porte.

\section{Relato de caso}

Um cão, buldogue inglês, 16 dias de vida, deu entrada 29 de fevereiro de 2016 no Hospital Veterinário da PUC - PR Campus de Toledo, apresentando dificuldade de se manter em estação, má formação do tórax com achatamento dorsoventral, dispneia, cianose, apatia, com relutância ao se alimentar e desenvolvimento corporal retardado (Figura 1)

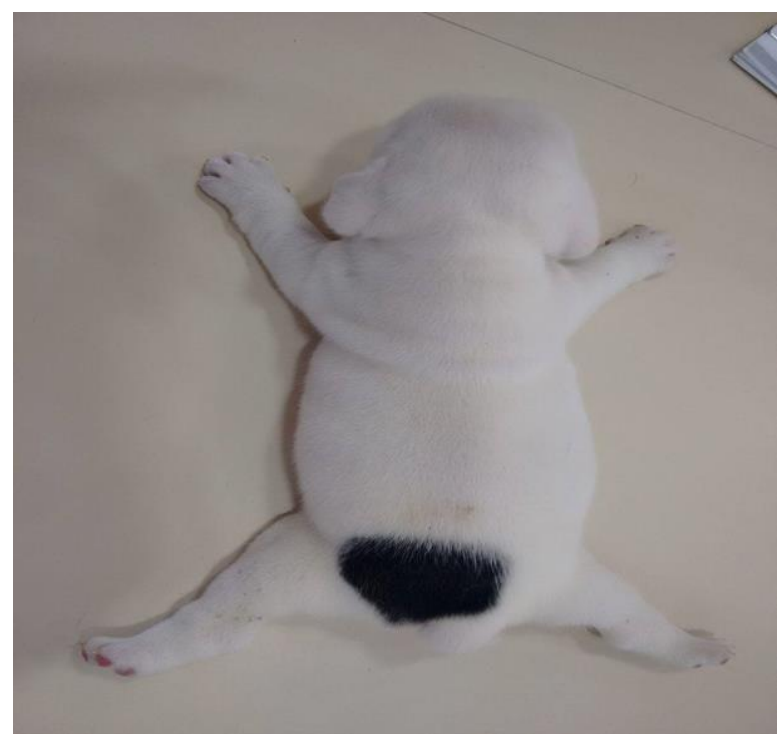

Figura 1. Pectus Excavatum em filhote de cão da Raça Buldogue Inglês. Fonte: Arquivo pessoal

$\mathrm{Na}$ anamnese, o animal apresentou dispnéia acentuada, progredindo para uma hipopnéia, ao longo da inspeção clínica. Ao ser realizado o exame clinico, o paciente apresentou mucosas hipocromadas e hipotermia sendo submetido a oxigenoterapia a $100 \%$ nas duas primeiras horas e a Unidade Terapêutica Neonatal para a estabilização clínica.

No exame físico específico, constatou-se uma deformidade no tórax, mais especificamente no osso esterno, um estreitamento ventro-dorsal.

O Diagnóstico foi baseado na anamnese e no exame clínico e físico geral, onde foi possível confirmar o caso de Pectus excavatum pelo exame 
radiográfico lateral do tórax (Figura 2) que ressaltou um grau de depressão subjetivamente na distância mínima entre a coluna vértebra e o aspecto dorsal do esterno.

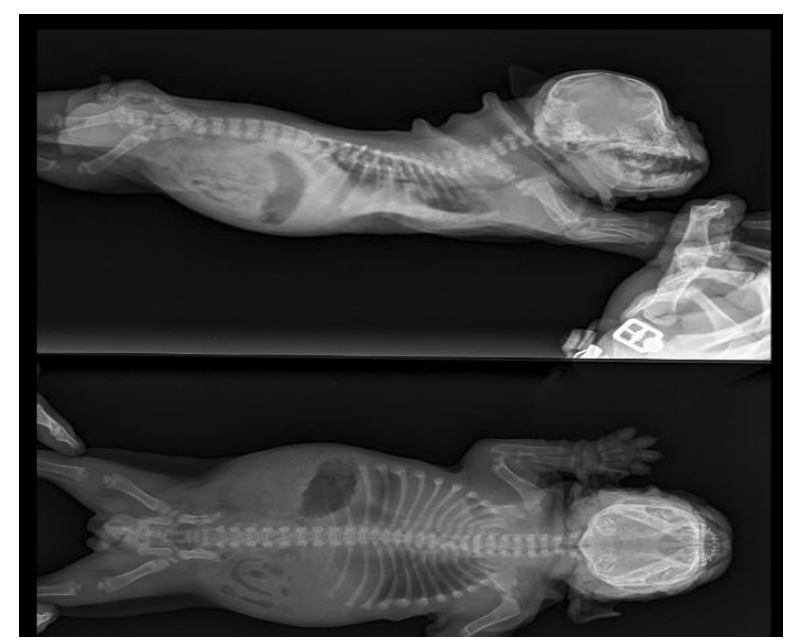

Figura 2. Radiografia do tórax látero-lateral e dorso-ventral de filhote de cão Buldogue Inglês com Pectus Excavatum. Fonte: Arquivo pessoal

Além da hipoplasia traqueal, concomitante foi diagnosticado um desvio cardíaco a esquerda, pelo exame radiográfico, ou seja, um leve desvio do coração que explicaria a disfunção dos seus batimentos e dificuldade em respirar.

Diante do laudo radiográfico, o tratamento de escolha foi a elaboração e execução de uma técnica não invasiva, possibilitando a compressão látero-lateral do tórax com um espaçamento ventral que facilitasse o reposicionamento anatômico do osso esterno. O tratamento de escolha foi a confecção de uma tala, utilizando faixas de gesso, que foi moldada ao redor do tórax onde permaneceria por 20 dias (Figura 3 ).

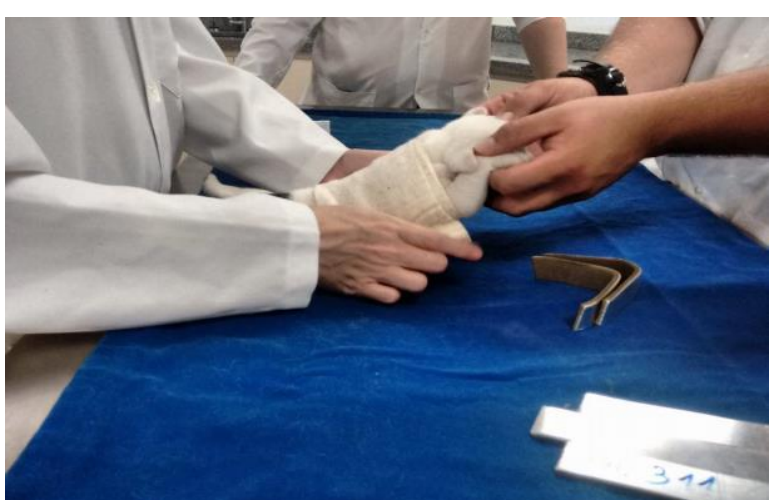

Figura 3. Colocação de tala em filhote de cão com Pectus Excavatum. Fonte: Arquivo pessoal
A tala foi confeccionada com o uso de faixas de gesso, moldadas em torno do tórax do paciente. $\mathrm{Na}$ face ventral da tala, foi colocado um cano de PVC, com a finalidade de moldar um espaço livre nessa região, para que com a compressão lateral do tórax através da faixa de gesso, e dos próprios movimentos respiratórios da paciente, o osso esterno se projetasse ventralmente, retornando à sua posição anatômica normal. Após a execução da tala, a paciente recebeu alta do HV.

$\mathrm{Na}$ primeira tentativa de elaboração da tala, houve uma falha em sua modelagem, o que acarretou no afrouxamento e deslocamento da mesma, 24 horas após a sua utilização pela paciente. Com isso, a paciente teve uma descompensação respiratória, precisando retornar ao HV. A paciente deu entrada no Hospital Veterinário com um quadro de cianose e hipopnéia, necessitando de oxigenioterapia por 12 horas, até que seus parâmetros respiratórios se restabelecessem.

Após o ocorrido, outra tala foi confeccionada, partindo do mesmo princípio da técnica utilizada anteriormente, porém, com a adaptação de uma espuma em formato de colete, colocada em baixo da faixa de gesso, elaborada especialmente com as medidas e necessidades da paciente, modelando mais estreitamente em torno de seu tórax.

Após 15 dias do início do tratamento com a segunda tala, a paciente apresentava ótimo estado geral, deambulação próxima da fisiológica e conformação anatômica do tórax próxima a normal. Optou-se pela retirada da tala aos 20 dias do início do tratamento (Figuras 4 e 5), para observar seu estado físico sem o apoio da tala. A paciente manteve-se em estação sem dificuldade, apresentou restabelecimento do padrão respiratório, conformação anatômica do tórax próxima a normal e melhora no desenvolvimento corporal, sendo notado uma dermatite bacteriana focal na lateral do tórax correspondente ao atrito da tala na região axilar.

Por fim o proprietário relatou estar satisfeito com a melhora do paciente, e ao realizar o exame físico após a retirada da tala foi possível visualizar o restabelecimento anatômico do tórax próximo ao normal, portanto o paciente recebeu alta pela equipe de atendimento do Hospital Veterinário, com devidas recomendações de cuidados em casa, tais como, alimentação adequada de consistência pastosa e ambiente não escorregadio. 


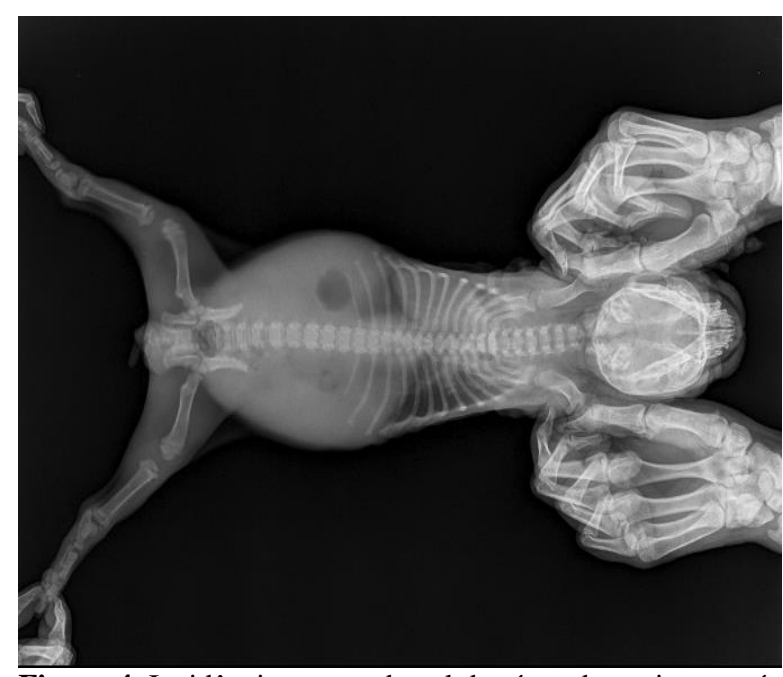

Figura 4. Incidência ventro-dorsal do tórax da paciente após o tratamento com a utilização da tala. Fonte: Arquivo Pessoal

Por fim o proprietário relatou estar satisfeito com a melhora do paciente, e ao realizar o exame físico após a retirada da tala foi possível visualizar o restabelecimento anatômico do tórax próximo ao normal, portanto o paciente recebeu alta pela equipe de atendimento do Hospital Veterinário, com devidas recomendações de cuidados em casa, tais como, alimentação adequada de consistência pastosa e ambiente não escorregadio.

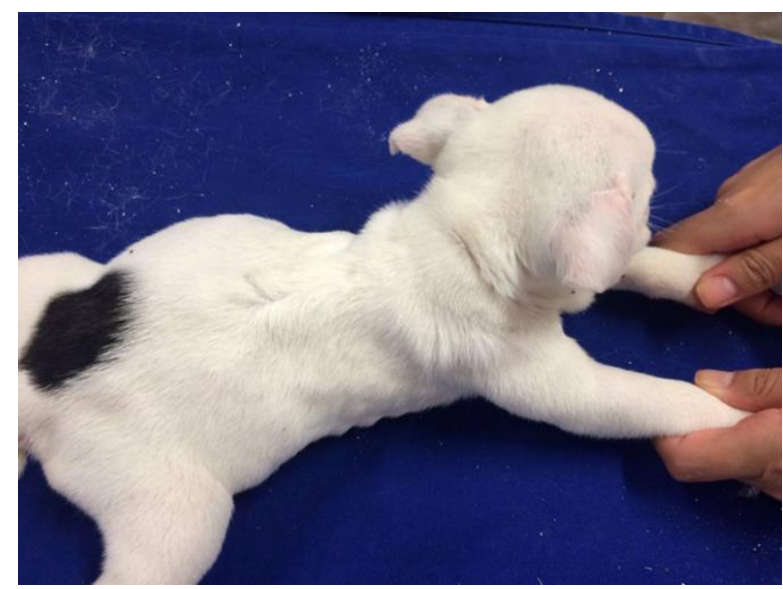

Figura 5. Paciente após a retirada da tala. Fonte: Arquivo pessoal

\section{Resultados e discussão}

Pectus escavatum (PE) é uma anormalidade da caixa torácica por crescimento anormal do esterno e cartilagens que se caracteriza por uma depressão condroesternal (Molina-Díaz \& Aguirre, 2014).

Salvo que a enfermidade pectus tende á uma baixa incidência na medicina veterinária, Pectus excavatum é mais comumente relatado do que o Pectus carinatum, caracterisado por protusão do esterno, sendo o Pectus carinatum mais comum no sexo masculimo (Martins et al., 2014), e o excavatum não sendo relacionado a predisposição sexual Fossum (2014).

Fossum (2014) afirma que a fisiopatologia da Pectus excavatum (PE) ainda são desconhecidas, mais a literatura propõe algumas teorias incluindo redução do tendão central do diafragma, anormalidades na pressão intrauterina e deficiência congênita da musculatura na porção mais cranialmente do diafragma, caracterizando então como uma doença congênita, contrapondo o que cita Molano et al. (2010) que entra as possíveis etiologias citadas a cima, a PE em seres humanos e primatas, considera-se um a questão hereditária, situação a ser transmitida por um gene autossômico dominante, sugerindo uma base heriditária em caninos e felinos.

A grande parte de animais com PE são assintomáticos, entretanto o defeito apresentando no tórax é geralmente palpável, despertando aos donos a procurarem um médico veterinário. Animais sintomáticos apresentam manifestações clínicas de diversos graus de severidade, desde retardo do crescimento, intolerância ao exercício, dispneia, taquipnéia, cianose e vômito (Galvão et al., 2013), semelhante ao caso em questão. No presente relato, o histórico clínico do paciente com dificuldade de se manter em estação, má formação do tórax com achatamento dorso-ventral, dispneia, cianose, apatia, com relutância ao se alimentar e desenvolvimento corporal retardado, corroborando com os achados dos autores supracitados.

Anormalidades cardiovasculares e respiratórias geralmente são encontradas em pacientes com PE, podendo ser resultantes do posicionamento anormal do coração devido a deformação do tórax, o que dificulta o retorno venoso restringindo a capacidade ventricular e diminuindo da reserva respiratória (Fossum, 2014). Tal como descrito na literatura, no relato citado em questão foi diagnosticado por exame radiográfico um leve desvio cardíaco à esquerda e hipoplasia traqueal.

A traqueia do Buldogue comumente é hipoplásica, outras raças braquicefálicas também apresentam traqueias mais estreitas do que a observada nos cães mesocéfalos ou dolicocéfalos. Entretanto acredita-se que isso seja consequência de uma embriogênese anormal ao invés de sequela de uma estenose mais cranial (Allemand et al., 2013). 
Cães braquicefálicos têm uma prevalência alta na manifestação do PE, o que poderia indicar que ele também está relacionado a um componente genético, alguns com hipoplasia traqueal ou outras manifestações enquadradas dentro da síndrome inominada (estenose nasal, hiperplasia do palato mole) de modo que tem vindo a acreditar que as variações no gradiente ventilatório, poderia contribuir para o desenvolvimento de doença (Molina-Díaz \& Aguirre, 2014).

Para o diagnóstico definitivo é relativamente simples, além do exame físico que é palpável a deformidade do esterno, se faz utilização do exame radiográfico do tórax, a avaliação objetiva da deformidade pode ser feita por dois índices: índice fronto-sagital e o índice vertebral conforme Fossum, 2014 indica na Tabela 1.

Tabela 1. Definição do Pectus excavatum (PE) em cães e gatos com base nos Índices fronto-sagital e vertebral.

\begin{tabular}{lcc}
\hline & \multicolumn{2}{c}{ Índice } \\
\cline { 2 - 3 } PE & Fronto-sagital & Vertebral \\
\hline Leve & $<2$ & $>9$ \\
Moderado & $2-3$ & $6-8.99$ \\
Severo & $>3$ & $<6$ \\
\hline
\end{tabular}

Fonte: Fossum (2014).

As radiografias torácicas revelam informação de alguma possível doença intratorácica associada, severidade da compressão pulmonar, e deslocamento mediastinal, e conjunto o grau de deslocamento do esterno, particularmente em relação à coluna vertebral (Martins et al., 2014).

$\mathrm{O}$ índice fronto-sagital é a medida em uma radiografia dorso-ventral ou ventro-dorsal, que consiste determinar a relação da largura do tórax, distancia entro o centro da superfície ventral da décima vértebra torácica até o ponto mais próximo do esterno, e se tratando do índice vertebral (Tabela 2) que é medido na projeção látero-lateral, que é a razão entre a distância entre da superficie dorsal também da décima vertebra até o ponto mais próximo do esterno (Molano et al., 2010).

Tabela 2. Indice fronto-sagital e vertebral normais

\begin{tabular}{lccc}
\hline & \multicolumn{2}{c}{ Cão } & \multirow{2}{*}{ Gatos } \\
\cline { 2 - 3 } Índice & Não-braquicefalicos & Braquicefalicos & \\
\hline Fronto-sagital & $0,8-1,4$ & $1,0-1,5$ & $0,7-1,3$ \\
Vertebral & $11,8-19,6$ & $12,5-16,5$ & $12,6-18,8$ \\
\hline
\end{tabular}

Fonte: Molano et al. (2010).

Fossum (2014) descreve que pelo índice fronto-sagital e o vertebral o PE pode ser classificado em leve, moderado e grave, podendo auxiliar na avalição objetiva da melhora dos parâmetros torácicos após a conduta médica diante do tratamento de escolha, contudo essas medidas não foram empreendidas no caso descrito.

A hipoplasia congênita é observada em alguns cães braquicefálicos, como Buldogue Inglês e Bullmastiff, entre tudo rara em gatos. O lúmen da traquéia é altamente afunilado, geralmente por todo o comprimento do órgão. $\mathrm{O}$ diâmetro pode ser inferior à metade do diâmetro da laringe, ou menor que a largura do terço proximal da terceira costela (Kealy et al., 2012).

Thrall (2013) cita que o diâmetro traqueal varia entre as raças e tamanhos dos animais, mas com relação as braquicefálicas esse diâmetro é consideravelmente menor, sendo a proporção média dos não braquicefálicos entorno de 0,20 0,03 comparado com 0,16 em raças braquicefálicas não descendentes dos Bulldogues.

Pelo exame radiográfico para diagnóstico da hipoplasia traqueal é ultilizado o método para determinar o diâmetro traqueotorácico, onde se utiliza a relação do diâmetro interno da traqueia ao nível da entrada torácica e a distância entre a borda ventral da primeira vértebra torácica e a borda dorsal do manúbrio, com essa medida é obtida a relação diâmetro da entrada torácica e o diâmetro traqueal na altura da entrada torácica, estando a relação normal ou superior á 0,16 para não constar a hipoplasia, no caso em questão a relação se deu em 0,04, indo de acordo com Souto et al. (2017).

A variação em Bulldogs foi de 0,07 a 0,21 e o menor valor encontrado em Bulldogs sem sinais clínicos de doenças respiratórias foi de 0,09 (Thrall, 2013).

Fossum (2014) afirma que para a escolha do tratamento deve-se levar algumas considerações, tais como o devido estado clínico do animal, idade, grau de aceitação do proprietário na questão do método terapêutico de escolha e possíveis afecções das vias aéreas.

Para o tratamento do PE inclui medidas terapêuticas como massagens compressivas ou utilização de talas externa compressivas no tórax podem ser opções para os graus moderados a severos de Pectus excavatum (Galvão et al., 2013).

A enfermidade pectus excavatum existe as condutas clínica e cirúrgica. $\mathrm{O}$ tratamento clínico consiste em estimular os proprietários a realizar regularmente uma compressão medial a lateral do tórax, caso o animal esteja gravemente dispneico 
deve-se realizar a oxigenoterapia, partindo desse princípio supracitados, foi realizado no paciente em questão a aplicação de uma técnica não invasiva, com a utilização de uma tala fazendo a compressão látero-lateral com um espaço medial para que o esterno retornasse a posição anatômica correta e fazendo o uso da oxigenoterapia pelos sinais clínicos apresentados pelo mesmo.

A aplicação de uma tala externa na face ventral do tórax é a técnica usada com mais frequência para corrigir o PE, quando o diagnóstico é feito precocemente em animais jovens, pelo fato das cartilagens costais e o esterno serem mais flexíveis, sendo essa uma técnica cirúrgica com a tração do esterno por fios de sutura colocado em torno do esterno e através de uma tala rígida, com risco de rompimento dos tecidos moles adjacentes e perfuração do coração, pulmões ou vasos torácicos enquanto se introduz a agulha em torno do esterno (Fossum, 2014).

Molano et al. (2010) e Fossum (2014) citam que o tratamento pode ser cirúrgico em animais jovem e dependendo de comprometimento cardiopulmonar em animais mais velhos; sendo esse último uma recuperação não muito satisfatória, quando optar pelo tratamento cirurgico e obtiver sucesso, é recomendada a castração, devido a sua etiologia ser desconhecida, animais afetados na mesmaninhada há possibilidade de herdabiliade.

Em caso de animais mais velhos, com o esterno menos maleável, podem não responder de maneira tão favorável o tratamento cirúrgico e clínico indicado em casos de PE, fazendo o uso da técnica cirúrgica de esternotomia parcial (Fossum, 2014).

\section{Conclusão}

O relato apresentado trouxe o caso de um filhote de Bulldogue inglês diagnosticado com Pectus excavatum (PE). A literatura abrange comumente casos de PE acometendo caninos de raças braquicefalicas, especialmente Bulldogs ingleses associados com hipoplasia traqueal e dextroposição cardíaca. O diagnóstico foi realizado através do exame físico e confirmado por meio do exame radiográfico, visto que a precocidade do diagnostico está diretamente ligada ao sucesso do tratamento.

O tratamento empregado foi o não invasivo, pelo uso de uma tala compressiva na região torácica, com ampla margem de segurança, a qual demonstrou bons resultados, mantendo a mobilidade adequada e com a capacidade respiratória sem apresentar dificuldades.

Sendo seu prognóstico excelente, o paciente foi indicado a castração respeitando a idade do animal, pelo fato do não conhecimento da etiologia da PE e pelos indícios de hereditariedade.

\section{Referências Bibliográficas}

Allemand, V. C. D., Quinzani, M. \& Berl, C. A. 2013. Síndrome respiratória dos cães braquicefálicos: relato de caso. Revista de Educação Continuada em Medicina Veterinária e Zootecnia do CRMV-SP, 11, 4247.

Fossum, T. W. 2014. Cirurgia de pequenos animais, 4 edn. Elsevier Brasil, São Paulo.

Galvão, A. L. B., Toni, M. C., Mostachio, G. Q., Rossi, A., Braz, L. A., N., D., Dias, D. P. M., Canola, J. C., Carvalho, M. B. \& TinucciCosta, M. 2013. Pectus excavatum em filhote de cão - Relato de caso. Acta Veterinaria Brasilica, 7, 1-5.

Kealy, J. K., McAllister, H. \& Graham, J. P. 2012. Radiologia e Ultrassonografia do Cão e do Gato. Manole, São Paulo.

Martins, D. B., Rietjens, L. H. \& Petrochi, D. 2014. Pectus carinatum em um cão. Acta Scientiae Veterinariae, 42, 1-4.

Molano, R. F. S., Ordóñez, F. J. P. \& Gallego, I. C. S. 2010. Descripción de un caso de la malformación congénita pectus excavatum en un felino doméstico. Revista Lasallista de Investigación, 7, 124-131.

Molina-Díaz, V. M. \& Aguirre, J. C. 2014. Pectus excavatum en un Bulldog Inglés: reporte de caso. CES Medicina Veterinaria y Zootecnia, 7, 65-70.

Souto, C. K., Martín, C. M., Ferrante, B. \& Campos, A. C. B. F. 2017. Métodos de diagnóstico por imagem para avaliação traqueal em pequenos animais. Revista Acadêmica: Ciência Animal, 13, 111-123.

Thrall, D. E. 2013. Textbook of veterinary diagnostic radiology. Elsevier Health Sciences, Philadelphia.

Article History:

Received 20 December 2017

Accepted 2 February 2018

Available online 23 March 2018

License information: This is an open-access article distributed under the terms of the Creative Commons Attribution License 4.0, which permits unrestricted use, distribution, and reproduction in any medium, provided the original work is properly cited. 